\title{
End-stage renal disease (ESRD)
}

National Diabetes Information Clearinghouse (NDIC)

\section{Definitions}

Kidney

Defined by National Diabetes Information Clearinghouse (NDIC)

\section{Source}

National Diabetes Information Clearinghouse (U.S.). (2009). The diabetes dictionary. [Bethesda, Md.]: U.S. Dept. of Health and Human Services, National Institutes of Health, National Institute of Diabetes and Digestive and Kidney Diseases, National Diabetes Information Clearinghouse.

Total and permanent kidney failure. When the kidneys fail, the body retains fluid. Harmful wastes build up. A person with ESRD needs treatment to replace the work of the failed kidneys. 